Provided for non-commercial research and education use. Not for reproduction, distribution or commercial use.

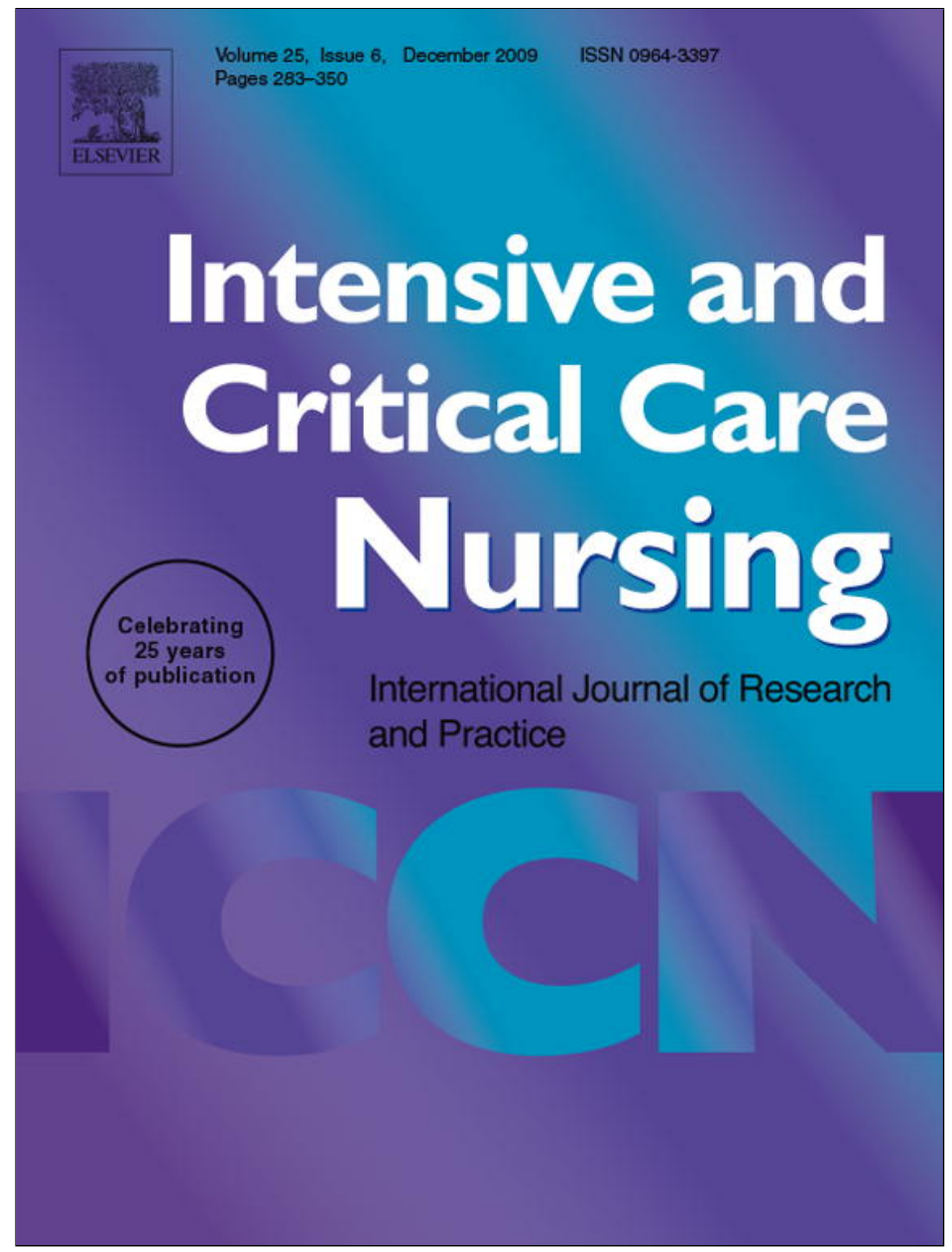

This article appeared in a journal published by Elsevier. The attached copy is furnished to the author for internal non-commercial research and education use, including for instruction at the authors institution and sharing with colleagues.

Other uses, including reproduction and distribution, or selling or licensing copies, or posting to personal, institutional or third party websites are prohibited.

In most cases authors are permitted to post their version of the article (e.g. in Word or Tex form) to their personal website or institutional repository. Authors requiring further information regarding Elsevier's archiving and manuscript policies are encouraged to visit:

http://www.elsevier.com/copyright 


\title{
Enjoying tactile touch and gaining hope when being cared for in intensive care-A phenomenological hermeneutical study
}

\author{
Maria Henricson $^{a, b, *}$, Kerstin Segesten ${ }^{a}$, Anna-Lena Berglund ${ }^{b, c}$, \\ Sylvia Määttäa \\ a University of Borås, School of Health Sciences, SE 50190 Borås, Sweden \\ ${ }^{\mathrm{b}}$ Karlstad University, Faculty of Social and Life Sciences, Department of Nursing, SE 65188 Karlstad, Sweden \\ c Faculty of Nursing Studies, Akerhus University College, NO 2001 Lillestrøm, Norway
}

Accepted 18 July 2009

\section{KEYWORDS \\ Intensive care; \\ Tactile touch; Phenomenological hermeneutic; \\ Narratives}

\begin{abstract}
Summary Touch has been a part of the healing process in many civilisations and cultures throughout the centuries. Nurses frequently use touch to provide comfort and reach their patients. The aim of this study was to illuminate the meaning of receiving tactile touch when being cared for in an intensive care unit. Tactile touch is a complementary method including the use of effleurage, which means soft stroking movements along the body. The context used to illuminate the meaning of receiving tactile touch was two general intensive care units (ICUs). Six patients, who have been cared for in the two ICUs, participated in the study. A phenomenological-hermeneutical method based on the philosophy of Ricoeur and developed for nursing research by Lindseth and Norberg [Lindseth A, Norberg A. A phenomenological hermeneutical method for researching lived experience. Scandinavian Journal of Caring Sciences, 2004;18:145-53] was chosen for the analysis. Data consisted of narratives, which were analysed in three recurring phases: naïve understanding, structural analyses and comprehensive understanding. Two main themes were found: being connected to oneself and being unable to gain and maintain pleasure. The comprehensive understanding of receiving tactile touch during intensive care seems to be an expression of enjoying tactile touch and gaining hope for the future. This study reveals that it is possible to experience moments of pleasure in the midst of being a severely ill patient at an ICU and, through this experience also gain hope.
\end{abstract}

(c) 2009 Elsevier Ltd. All rights reserved.

\footnotetext{
* Corresponding author at: University of Borås, School of Health Sciences, SE 50190 Borås, Sweden. Tel.: +46 3343547 39; fax: +46334354446.

E-mail address: Maria.Henricson@hb.se (M. Henricson).
} 


\section{Introduction}

Touch has been a part of the healing process in many civilisations and cultures throughout the centuries. Touch as a therapy is one of the oldest forms of treatment in the world, first described in China during the second century BC (Taylor, 1991). Nurses frequently use touch to provide comfort and reach their patients. Often, this human and warm contact is an expression of comfort and communication (Benner, 2000; Field, 2000). In intensive care, nurses use touch when caring for patients, where a hug or a pat on the cheek are experienced by the patients as human warmth and consideration (Wåhlin et al., 2006). On the other hand, patients who have been cared for in an intensive care unit (ICU) also describe their feelings of receiving intensive care with words such as "frightening", "terrifying" (Löf et al., 2006), "frustrating", "like being in prison" (Magnus and Turkington, 2006) and "being alone"' (Corrigan et al., 2007). Patients also remember the environment as never being really quiet or peaceful (Löf et al., 2006).

To relieve the patients' feelings of distress and promote comfort, complementary methods, such as foot massage and touch massage, have been used (Hayes and Cox, 1999; Johansson Hovstadius et al., 2005). Tactile touch has slowly been introduced as a complementary method in Swedish ICUs, but it is not a routine part of the nursing care and is rarely been studied. However, the treatment has been evaluated in other groups of patients, for example, women with diabetes whose levels of blood glucose decreased after tactile touch (Andersson et al., 2004). Women during the latent phase of labour could relax and recover their strength after tactile massage (Andrén et al., 2005) and patients with anorexia nervosa felt a sense of relaxation and relief (Axelsson and Määttä, 2007). Furthermore, women with breast cancer experienced reduced nausea (Billhult et al., 2007) after the treatment and patients with a stroke made clear progress in terms of reduced incontinence, improved mobility and hygiene when they received tactile massage (Olsson et al., 2004). None of the studies reported any negative effects of the treatment.

In this paper, tactile touch is used in much the same sense as Taylor's (1991) definition of effleurage. Effleurage is used when the purpose is to touch the skin and implies slow stroking with firm pressure, mainly performed with the flat of the hand with fingers close together. Tactile touch should not be compared to Swedish massage, which uses pressure and kneading (Taylor, 1991). In Sweden, tactile touch is performed by trained touch therapists. Tactile touch as a session starts with preparation (Henricson et al., 2006) before the touch can be given, followed by the performance of the touch and ends with a moment of calmness. Initially, the touch therapist prepares the room; lights are dimmed; soft relaxing music is played; curtains are drawn to provide privacy; towels are prepared in a heating cabinet and staff are encouraged to keep the environment as quiet as possible. During tactile touch, the patient's body is wrapped in towels so they will not feel cold or be unnecessarily exposed. Only the part of the patient's body that is being touched is uncovered. To achieve positive effects, patients need repeated treatment for at least 30 minutes (Corner et al., 1995; Wilkinson et al., 1999). Tactile touch as a comple- mentary method in general and in ICUs in particular, is an under-researched area. Therefore, little is known about the patients' experiences of being exposed to this treatment.

\section{Aim}

The aim of the study was to illuminate the meaning of receiving tactile touch when being cared for in an intensive care unit.

\section{Method}

\section{Participants and setting}

The study was conducted as a part of a larger project, in which 44 patients ( 21 in the intervention group and 23 in the control group) from two general ICUs in Sweden participated (Henricson et al., 2008a,b). Before the study start, all conscious patients gave their informed consent. In case of a semi- or unconscious patient (MAAS, Motor Activity Assessment Scale, 2-4), the touch therapist or the primary nurse consulted the patients' next of kin for information about the patient's general opinions both on physical touch and research. The patients who were semi- or unconscious by the time of the study were asked for informed consent before discharge or two to three days after leaving the intensive care unit. None of the patients objected afterwards. The patients received a one hour, daily (noon $-13.00 \mathrm{hrs}$ ) tactile touch intervention, for five successive days. On day 1 , tactile touch was given on the hands and feet; on day 2 on the hands, feet and stomach and on days 3, 4 and 5 on the head, face, stomach, chest, arms, hands, legs and feet. Five touch therapists in the ICUs, three nurses and two enrolled nurses with the same training in tactile touch performed the tactile touch.

The inclusion criteria for this study were the following:

- To have received tactile touch when being cared for in an intensive care unit

- To remember receiving the touch

- To be willing to take participate in a interview

- To have been discharged from hospital

Twenty-one patients met the first inclusion criteria, as they had received tactile touch. Since three of them had no memories of their time in the ICU and 11 patients had died during intensive care or afterwards, seven remained. When discharged from the hospital, the remaining patients were asked initially by letter and afterwards by telephone, to participate in the study. One patient declined, leaving six patients, three women and three men aged between 54 and 78. The patients suffered from heart disease, heart surgery or intestinal surgery and the length of stay was 6-51 days (mean 22 days). Four patients were cared for in rooms with two beds and two patients were in rooms with four beds. Five of them needed support from a mechanical ventilator and required sedative drugs. All were responsive to their names and to touch and none was unconscious when the tactile touch was performed. 


\section{Data collection}

The interviews were conducted at a time and place chosen by the six participants. Four of the patients preferred to be interviewed at home, one was interviewed in a room near the intensive care unit and one at his place of work. The patients were contacted for the interview three to four months after hospital discharge. This is of great importance, since the aim of the study was to illuminate the meaning of tactile touch. If the experiences of tactile touch were to be examined just a few days after discharge from the ICU, the patients would have risked fragmentary memories or a lack in recollection due to residual effects of sedation (Löf et al., 2006). In the present study, all participants needed rehabilitation after their hospital discharge, which is why three to four months was considered a suitable time frame for the research interviews to take place.

The interviews were undertaken between April 2006 and March 2007. The participants were asked to narrate their experiences of tactile touch using a broad and open question: "Could you, please, tell me about your experience of receiving tactile touch during your stay in the intensive care unit?" Reflections and memories from and about the tactile sessions and what it meant for them afterwards were sought in the interviews. The participants narrated their experiences with a minimum of interruptions. Open-ended follow up questions were only used to encourage the narrative, for example, "Can you tell me more? Can you give some examples?' 'The concept tactile touch was written on a piece of paper and showed to the participants during the interview in order to enable them focusing on the concept (Thomsson, 2002). In case of fragmentary memories, the participants were asked questions, such as "Can you tell me how you experienced the room?" ' and "'Do you remember how your body reacted during the tactile touch?"' to encourage the narration (cf. van Manen, 1990). The interviewer strived to keep the openness and let the participant "hold the floor"' (van Manen, 1990). The tape-recorded interviews lasted 45-60 minutes and were transcribed verbatim. Nonverbal expressions, such as laughter and pauses were noted in the transcripts.

\section{Data analysis}

A phenomenological hermeneutic method based on Ricoeur's (1976) philosophy and developed for nursing research by Lindseth and Norberg (2004) was chosen for the analysis. This research method is essentially about illuminating the meaning of lived experiences of phenomena in people's lifeworld. An important and natural way that people use for communicating a meaning is through narratives (Mishler, 1991). Therefore, the data in this study consist of narratives with interviewees. Ricoeur (1998) and Lindseth and Norberg (2004) claim that in order to illuminate the meaning of the lived experience it has to be fixed in a text (transcribed) and interpretation is needed. Furthermore, the experience of a phenomenon will always remain private, but its meaning can become public by the interpretation (Ricoeur, 1976).

According to Ricoeur (1976), the researcher should move through three methodological steps in order to open the way into the interpretation process. Initially, the interviews should be read several times, as a naïve reading. This step aims to acquire a sense of the whole, a first understanding or a guess, related to the aim of the study (Lindseth and Norberg, 2004). Ricoeur (1976) sees such an interpretation as a form of "dress off" so that the researcher can be open to the otherness and meaning of the text. The first naive understanding is formulated in phenomenological language and guides the structural analysis, which is the second step in the interpretation process (Lindseth and Norberg, 2004). The structural analysis moves back and forth between the parts and the whole of the text and continues as long as a new and deeper meaning can be grasped. This second step can ratify, reject or confirm the impression from the naive understanding (Lindseth and Norberg, 2004). The final step of the interpretation process, the comprehensive understanding (interpreted whole), takes into account the naïve understanding, the structural analysis and the researchers' preunderstanding (Ricoeur, 1976, 1998). There is a movement between the understanding and the explanation of the text through the three methodological steps in the interpretation process.

\section{Ethical approval}

All participation was voluntary and all patients gave their informed consent. The participants were informed about the nature and purpose of the study and the intended use of research data. They were assured that they could withdraw from the study at any time without recrimination. The participants were also assured that data would be treated in strict confidence; a number would denote each participant and the participants' identity would not be disclosed in the final report or in any publication. Ethical approval was given for the larger project by the Regional Ethical Review Board in Gothenburg, Sweden (D. No: 411-04).

\section{Findings}

\section{Naïve understanding}

Each interview was read thorough several times to capture the first understanding of the text as a whole, from this a first naïve interpretation was conceived. In this step of the analysis, the researchers considered their preunderstanding as a resource. The text showed that the meaning of receiving tactile touch was experienced as creating an imagined room of togetherness, comprising the patient and the touch therapist. The meaning of this imagined room seemed to be a private area with the opportunity to focus on oneself. It appeared to be quite, calm and dark and loaded with a sense of safety. Nightmares, thoughts and worries about illness seemed to disappear in the imagined room. The imagined room was surrounded by imagined walls, which locked out disturbance from other patients and/or staff during the tactile touch. Feelings of loneliness and being abandoned appeared when leaving the imagined room after each tactile touch session and later after the discharge from the ICU. 
Table 1 Description of parts of the theme.

\begin{tabular}{|c|c|c|c|}
\hline Meaning units & $\begin{array}{l}\text { Condensed meaning } \\
\text { units }\end{array}$ & Subthemes & Themes \\
\hline $\begin{array}{l}\text { Other patient did not disturb during } \\
\text { the tactile touch... no it is not } \\
\text { possible because when she (touch } \\
\text { therapist) doing this... you } \\
\text { are...//...It is so wonderful you } \\
\text { see...You don't care about } \\
\text { anything else. . . no I did not care } \\
\text { about them.. }\end{array}$ & $\begin{array}{l}\text { Other patients were in } \\
\text { the periphery during the } \\
\text { tactile touch }\end{array}$ & Being focused on oneself & Being in togetherness \\
\hline $\begin{array}{l}\text { I experience massage and tactile } \\
\text { touch as completely } \\
\text { different.../I... When she (touch } \\
\text { therapist) touched my feet and legs } \\
\text { my whole body felt good. . both the } \\
\text { body and the soul. When I receive } \\
\text { massage the soul does not feel } \\
\text { good... }\end{array}$ & $\begin{array}{l}\text { When comparing } \\
\text { massage and tactile } \\
\text { touch the most marked } \\
\text { difference was that } \\
\text { during tactile touch both } \\
\text { body and mind felt good }\end{array}$ & $\begin{array}{l}\text { Being in harmony in } \\
\text { one's body } \\
\text { Being in harmony in } \\
\text { one's mind }\end{array}$ & Enjoying comfort \\
\hline $\begin{array}{l}\text { She [the touch therapist] did it } \\
\text { [tactile touch] for so long time on } \\
\text { every part of my body. That's why } \\
\text { l enjoyed it so much. This tactile } \\
\text { touch was not something fast; it } \\
\text { took time... }\end{array}$ & $\begin{array}{l}\text { In order for the patient } \\
\text { to enjoy the tactile } \\
\text { touch, it was necessary } \\
\text { for the touch therapist } \\
\text { to take her time when } \\
\text { performing the touch }\end{array}$ & Enjoy slowness & Being connected to time \\
\hline
\end{tabular}

\section{Thematic structural analysis}

A thematic structural analysis was carried out to validate and adjust the naïve interpretation and to reach a deeper meaning of receiving tactile touch. In this step, the interpreters strove for an objective attitude and tried to withhold their pre-understanding. Meaning units were identified, condensed and organised in the text. The meaning units were read through and reflected upon with the background of the naïve interpretation. The question used to analyse the text was, "what is the meaning of receiving tactile touch and being in an imagined room?' ' Condensed meaning units were created and read through to detect similarities and differences. Finally, the condensed meaning units were abstracted to subthemes, themes and main themes. An example of the analysis is presented in Table 1. An overview of the main themes, themes and subthemes is shown in Table 2 . The headline in bold refers to the main themes; the text in italics refers to the themes and the underlined text in the result section refers to the subthemes in the study. The numbers within brackets refer to the participants while square brackets are used to clarify the language.

\section{Being connected to oneself}

Being connected to oneself was illustrated in the text by narrations of being in touch with one's body and mind. The feeling seems to be related to taking pleasure in the tactile

Table 2 An overview of main themes, themes and subthemes.

\begin{tabular}{|c|c|}
\hline $\begin{array}{l}\text { Being connected to oneself } \\
\text { Enjoying comfort } \\
\text { Being in harmony in one's body } \\
\text { Being in harmony in one's mind } \\
\text { Being connected to memories }\end{array}$ & $\begin{array}{l}\text { Being unable to gain and maintain pleasure } \\
\text { Being exposed to annoying stimuli } \\
\text { Being exposed to unpleasant feeling } \\
\text { Being moved to another surrounding }\end{array}$ \\
\hline $\begin{array}{l}\text { Being connected to time } \\
\text { Enjoy slowness } \\
\text { Longing for continuity } \\
\text { Being in reality }\end{array}$ & $\begin{array}{l}\text { Being exposed to an annoying environment } \\
\text { Being interrupted by the staff and the surroundings }\end{array}$ \\
\hline $\begin{array}{l}\text { Being in togetherness } \\
\text { Being in privacy } \\
\text { Being in reciprocal trust } \\
\text { Being privileged } \\
\text { Being focused on oneself }\end{array}$ & $\begin{array}{l}\text { Being left without comforting touch } \\
\text { Being abandoned } \\
\text { Being one among many again }\end{array}$ \\
\hline
\end{tabular}


touch, a feeling in which pleasant memories, the sense of time and being in togetherness are intertwined.

Enjoying comfort

Receiving tactile touch means to experience enjoyable comfort which implies being in harmony in one's body. The body, often experienced as weak and lacking strength, becomes "alive" during tactile touch. The entire resurrected body enjoyed the comfort and not only the part that was touched for the moment. A man who spent several days in an ICU before he received the touch narrated the reaction of his body:

"This thing she has been doing with me gave me an increased sensitivity or an increased blood circulation and bring the lifeless body to life.../ .and a relief of pain of these exposed parts of the body' '(2)

Another aspect, which contributed to the fact that tactile touch was experienced as comfortable in body and mind, was the meaning of how the touch therapist performed the touch. The touch therapists' soft and caring hands and the use of their hands as a "caring implement" created an "extraordinary" comfort in some parts of the body, especially in the hands and feet.

Enjoyable comfort also implies being in harmony in one's mind, which means that several senses, apart from the tactility, were stimulated when receiving tactile touch. This was elucidated in contrast to the classic massage, which was defined as a powerful treatment aimed to stimulate the muscles of the physical body and associated with pain relief in a specific part of the body. In comparison, tactile touch was experienced as an enjoyable comfort for the whole body. A woman who had experienced classic massage made the following statement:

"It is not the same [tactile touch and massage]...// She [physiotherapist] uses pressure and it is painful...// tactile touch was something nice and soft. The physiotherapist presses hard...but in the ICU it was nice and soft..."'(3)

In common with this statement, another woman expressed that classic massage and tactile touch gave different experiences.

I experience massage and tactile touch as completely different...// When she [the touch therapist] touched my feet and legs my whole body felt good...// and the soul felt good too...both the body and the soul. When I receive massage the soul does not feel good (6)

This enjoyable comfort in body and mind induced a harmony and a feeling of internal well-being, which seemed to stay with the patient even when the touch therapist had ended the tactile touch session and left the room. A patient described her internal harmony after tactile touch as a state of sorcery, which was interrupted in the moment the staff came in and started to mess up in the room.

The soft music played during the tactile touch session was experienced as a bonus which contributed to the enhancement of the enjoyable feelings and gave pleasurable memories. A patient, who enjoyed the music and heard it again when he was awake, narrated that he was connected to memories of tactile touch from the time he was sedated:

I think that I would not have remembered the touch in such details if it had not been for the music. Therefore, the music in combination with the touch made it feel so good... / / The music aroused my memory in some way... (5)

\section{Being connected to time}

Being connected to time during tactile touch means to have a moment when the time stands still, which brings even more pleasure to the tactile touch. In the ICUs fast track, the tactile touch session makes it possible to enjoy slowness. The touch was experienced as a slow caring act during which the touch therapist allowed the stroking to take time. A woman who appreciated that tactile touch took time narrated:

"She [the touch therapist] did it [tactile touch] such a long time on every part of my body. That's why I enjoyed it so much. This tactile touch was not something fast; it took time"' (1)

There was a wish to be connected to time continuously through the tactile touch sessions. The time reserved for the touch was experienced as meaningful and the patients expressed an aspiration to get further pleasurable moments and longed for continuity in the sessions. A patient narrated:

"I long for her...// I would like to have more of this touch. I would like to disappear calm and peaceful. She was there almost an hour and it was so amazing. . . and it lasted for four really wonderful days" (1)

To experience the moment of tactile touch as being in reality was another meaning of being connected to time. Feelings of being "here and now" made the patients feel comfortable and secure. A patient who had nightmares and unreal experiences during his stay in the ICU pointed out:

"I remembered it [tactile touch] like it was present time...compared with the nightmares which were past time..."'(4)

\section{Being in togetherness}

Being in togetherness seemed to be a special one-to-one relationship created by the patient and the touch therapist during the tactile touch. This relationship gave a moment of privacy when no one else, except the two persons involved, were present in the imagined room. The togetherness promoted feelings of security and reciprocal trust, which contributed to a possibility to take control over the situation since the touch therapists retained their integrity. A patient expressed these feelings as follows:

"Nobody else was there... Only the touch therapist who did it [tactile touch]... No members of the staff were there and I did not consider it as a problem" (3)

The moment of togetherness with the touch therapist also contributed to feelings of being privileged, which meant to be treated with respect, asked for consent and 
be given the opportunity to lie down and relax without demands to perform in return. Nothing was expected of the patients in this relationship, which allowed them to be focused on themselves. Annoying stimuli from the surrounding, such as noise, as well as worries about illness and the uncertain future were set aside. Two patients expressed their experiences:

"I remember the room in the ICU as noisy when the touch therapist was not there. . / / I was pleased with the calm atmosphere during the touch" (5)

"When she [the touch therapist] began to give me tactile touch it was only the touch and nothing else... everything else disappeared..." (1)

To be able to fully enjoy the tactile touch session and experience the pleasure, the patients wished to be more alert. A man who narrated that he was missed out by the pleasure of tactile touch during the time he was sedated said sadly:

For the matter it is a pity that I was not more alert during the touch so I could really experienced the positive effect...it should have been a really good experience...// if you start too early with it I haven't got the chance to experience the positive effects in the same way... you experience pleasurable things the same time as you are sleepy.

\section{Being unable to gain and maintain pleasure}

Being unable to gain and maintain pleasure in the imagined room was illustrated in the text by narrations of distraction which appeared during the tactile touch or in conjunction with the end of the tactile touch session. The feeling of being unable to gain pleasure was related to the unpleasant feeling of the music which was experienced as annoying. On the other hand, the feeling of being unable to maintain pleasure was related to the environment which caused disturbances and the feeling of being left without comforting touch.

\section{Being exposed to annoying stimuli}

The soft music played during the tactile touch session was relaxing on the one hand, but on the other hand it could also be experienced as a hindrance and annoying stimuli, instead of contributing to the pleasure. The music was "too much" in the situation of severe illness and could lead to an unpleasant feeling. The illness and all medications alter the patient's sensitivity when it came to sounds. Hence, some patients preferred tactile touch without music.

Being exposed to annoying stimuli was also illustrated in the text by feelings of being moved to another surrounding by the music, for example, imagining being moved to a foreign temple covered with strange carpets and textiles. This movement gave an unpleasant feeling of having lost reality. Not only the music per se, but the kind of music caused unpleasant feelings. One patient claimed:

I didnit like this kind of music... To my opinion it was whining in its tunes. Whining and perhaps some more irritating... // Music from the 1940's and 50's would have been more fun. . you should ask people about their preferences concerning music when they are lucid... (2)
Being exposed to an annoying environment

A wish to prolong the feeling of well-being for a while and keep the silence in the room when the tactile touch session was over was expressed in the text. The wish was unfulfilled as the patients experienced that they were interrupted by the staff and the surroundings as soon as the tactile touch session was over. A patient pointed out:

When she [touch therapist] left and they [the staff] came back again... I wanted to be alone for a while... the spell was broken... However, it was necessary for them to come back and we could not wait until the captivation disappeared by itself...I did not say anything...But I wish they had waited a little while... (1)

\section{Being left without comforting touch}

Patients' inability to maintain pleasure also meant being left without comforting touch. When the touch therapist ended the tactile touch session after an hour, feelings of being abandoned and being lonely were expressed. When the comforting touch was over after five days, the body became stiff again and the well-being turned to discomfort, e.g. seeing unreal sights and having nightmares as soon as closing eyes. The feelings of being abandoned and alone arose when the patient left the ICU and got cared for in another ward.

"You got tactile touch for a few days and then back to medicine ward and nothing happened... You lie there and the body gets stiff and unable to move again' (3)

Moreover, the feeling of being in togetherness with the touch therapist and being acknowledged as a unique person got lost when the sessions were over and the touch therapist ceased to come. A man who liked to have more sessions of tactile touch pointed out:

She [touch therapist] stopped the tactile touch...she had already finished when I wanted more...there was no continuation... / / I think that they should follow the patient from the ICU to the next ward.... it would have been better with tactile touch on the ward because when I was there I just lay in my bed and was unable to do anything (2)

Another aspect of being left without comforting touch appeared to be the feeling of being one among many again. At the end of the tactile touch sessions, the patients, feelings of being privileged during the tactile touch were replaced by feelings of loneliness. When the touch therapist left the room for the day, also when the five-day period of tactile touch was over, the imagined room disappeared and the patients received the same care as everybody else in the ICU room. There own needs had lower priority and the need for a quiet and peaceful environment was set aside.

\section{Comprehensive understanding}

The last step of the analysis was the comprehensive understanding (interpreted whole) (Lindseth and Norberg, 2004). The text was read again as a whole and the research question, the preunderstanding, the reflection of the naïve understanding and the results of the structural analysis were 
taken under consideration. The interpretation of receiving tactile touch during intensive care seemed to be an expression of enjoying tactile touch and gaining hope for the future.

In the imagined room, created by the patient and the touch therapist during the tactile touch sessions, patients experienced both pleasure and unpleasant moments. Both experiences existed in the imagined room, but not at the same time. A pleasant moment could promote hope, but unpleasant moments did not necessarily cause feelings of hopelessness. In both cases (pleasant and unpleasant moments), the patients could experience a strengthened sensibility in their body as well as mind and felt connected to reality instead of having hallucinations or nightmares.

To revise, widen and deepen our understanding of the interpreted whole, we used literature that seemed appropriate. The patients' experience can be understood from the philosophy of ethics formulated by Aristotle (Crisp, 2000). Aristotle's view on ethics concerns the good and focuses on the nature of the human good or human happiness. It also includes elements of common conceptions of happiness, such as pleasure: "what are pleasant are the activity of the present, the hope for the future and the memory of the past"' (Crisp, 2000, p. 173).

According to Aristotle pleasure has to be occasioned by an activity, e.g. the situation of the tactile touch session. It takes time to gain the feeling of being in pleasure, which is not a condition produced suddenly, from one moment to another (Crisp, 2000). The experience of pleasure can interrupt the flow of time, according to Aristotle (Crisp, 2000). Tactile touch might be seen as an example of Aristotle's thoughts in this regard. Tactile touch session is an activity which takes time and patients experience that they have a moment when the time stands still. The touch is a slow caring act and when performing the tactile touch, the touch therapist allows the stroking to take time.

Another meaning of receiving tactile touch was that patients enjoyed comfort through the harmony in body and mind. Various human senses are involved in touch therapy, e.g. the tactile senses, the hearing senses and the eyesight. The involvement of the majority of senses might strengthen the patients' experience of pleasure, which can also be interpreted in the light of Aristotle's (Crisp, 2000) philosophy, in which the body is considered as a setup for pleasure. However, when the tactile session was over, patients expressed feelings of being abandoned and lonely and they wished a continuation of the tactile touch sessions. These wishes were not fulfilled because a pleasurable moment cannot last forever as explained by Aristotle. Being abandoned could be "one side of" the pleasure since humans are not capable of continuous pleasurable activity.

The pleasurable activity, tactile touch, could also contribute to increasing patients' hope. All humans have the potentiality of hope, but need an activity to gain this hope (Crisp, 2000). When the touch therapist performs the tactile touch session, patients seem to experience hope for the future, as interpreted in the present study. Noteworthy is that the meaning of the concept "future", that can comprise a short perspective for patients in an ICU, e.g. having a hope to be able to sleep without nightmares or thoughts of their illness. According to Gravlee (2000), Aristotle expresses that a person can be hopeful when they has the opportunity to get rid of their fear or a danger at hand.

In addition to being able to focus on other matters than nightmares, the patients' body responded and "became alive" during the tactile touch session. This response from a sick, stiff and tired body might contribute to the hope to feel better, to see possibilities to recover and find a meaning in life. In the absence of hope, it is difficult to restore health. The importance of hope in the process of restoring health is illuminated by Jevne (1991) who further developed Marcel's $(1965,1967)$ philosophy of hope where health and hope are intimately interacted and that is impossible to gain health without having a hope.

To further illuminate the meaning of hope in this paper, Marcel's $(1965,1967)$ philosophy has been used. Patients' experience of being in togetherness and the special oneto-one relationship created with the touch therapist during tactile touch are in line with Marcel's (1967) philosophy according to which hope is genuine when there is a close interaction between a giver and a receiver. The interaction requires that the giver is truly present, which Marcel denotes "being available". To be available involves an activity and a readiness to be at someone's service (Marcel, 1965). During the tactile touch session, the touch therapist could be interpreting as giver and the patient as receiver. The touch therapist is truly present and available for the patient and this availability opens the way for hope.

\section{Discussion}

The findings of the present study show that receiving tactile touch is experienced as a pleasurable moment, which gives hope to the patients during intensive care. These findings have some similarities with findings in previous research on tactile touch, such as a moment of relaxation and a pause in the course of having a specific disease (cf. Andrén et al., 2005; Axelsson and Määttä, 2007).

In an ICU, there seem to be limited possibilities to experience moments of pleasure in the midst of being critically ill (Almerud et al., 2007; Gjengedal, 1994). Patients are being thrown into a situation where their existence is threatened (Storli et al., 2008) and the situation could be experienced as extremely stressful (Rotondi et al., 2002). The situation has been described by the patients as being in a state of chaos, resulting in feelings of extreme instability, vulnerability, fear (Granberg et al., 1998), confusion and anxiety (Ringdal et al., 2006; Rotondi et al., 2002). These feelings could be interpreted to be both unpleasant and uncomfortable.

A strong link has been identified between memories from intensive care treatment and the incidence of subsequent post-traumatic stress disorder (PTSD) (Cuthbertson et al., 2004; Griffiths et al., 2005). It is suggested that a way for the patient to prevent PTSD is to realise that the delusion is not real (Jones et al., 2001). The patients in the present study experienced the moment of tactile touch as being in reality. Feelings of being "here and now" made the patients feel comfortable and secure. Thus, tactile touch might help the patients to take control over their own bodies and minds. Furthermore, when patients have someone or something to live for during treatment in intensive care, they seem to 
become stronger (Storli et al., 2008). The touch therapist (someone) and tactile touch (something) might contribute to give the patient hope for the future and perhaps also strength to get well.

Studies that deal with patient's experience of hope in intensive care are few, although the meaning and importance of hope for family members and nurses has been emphasised by several authors (Gelling, 1999; Gelling et al., 2002; Verhaeghe et al., 2007a, 2007b).

\section{Study limitations}

In this study, the first author (MH) had a pre-understanding as an experienced intensive care nurse and a qualified touch therapist. MH gave tactile touch to three of the six patients interviewed in the present study. Two of them remembered the author, which might have affected the interviews. The participants might have tried to please the interviewer, who had given them tactile touch, or perhaps avoided responses that might have lead the interviewer to evaluate their experience adversely. This fact might weaken the trustworthiness. However, from a Ricoeurian perspective, it is impossible as an interpreter to ignore one's pre-understanding, i.e. the interpreter cannot understand something in a way that someone else other than themselves would do. Thus, the process of reflecting upon a text and interpreting it has its starting-point in the researcher's personality. Or rather, one's pre-understanding ought to be seen as a resource for the interpreter when conducting the naïve interpretation and used as an interpretation tool for the comprehensive interpretation. In the structural analysis, the interpreter ought to have an objective attitude and be aware of the pre-understanding (Ricoeur, 1976).

Furthermore, none of the co-authors worked in intensive care or performed tactile touch. Throughout the analysis and interpretation, all authors worked closely together to strengthen the interpretation by contesting and supplementing each other's readings (Malterud, 2001). This process of reflexivity was undertaken to enhance the dependability, conformability as well as credibility, and thus contributing to the collective trustworthiness (cf. Lincoln and Guba, 1985).

The limited number of participants is a limitation of the study. The findings could have been different if more patients had been interviewed, although six patients were probably enough to capture possible implications of receiving tactile touch, as displayed by the text.

\section{Conclusion}

An intensive care unit could be viewed as an environment where the patients are severely ill, activities and sounds may be frightening and experiences of pleasure seldom occur. However, this study reveals that it is possible, for an intensive care patient, to experience moments of pleasure and, through this experience, also gain hope. After individual assessment, tactile touch can therefore be added as a complementary method to the armoury of caring acts available for these patients.

\section{Conflict of interest}

The authors have no conflict of interest.

\section{Funding/Sponsorship}

The research was supported by grants from University of Borås, Sweden; The Local Research and Development Council at Södra Älvsborg, Sweden; The Swedbank Foundation, Borås, Sweden. The sponsors have had no involvement in the study design, in the collection, analysis or interpretation of the data or the decision to submit the manuscript for publication.

\section{Acknowledgements}

We would like to thank the patients for participating in this study. We also want to thank Christine Forssell and Ellinor Larsen who revised the English.

\section{References}

Almerud S, Alapack RJ, Fridlund B, Ekebergh M. Of vigilance and invisibility - being a patient in technologically intense environments. Nursing in Critical Care 2007;12:151-8.

Andersson K, Wändell P, Törnkvist L. Tactile massage improves glycaemic control in women with type 2 diabetes: a pilot study. Practical Diabetes International 2004;21:105-9.

Andrén K, Störholt L, Lundgren I. Women's experiences of tactile massage during the latent phase of labour [Swedish]. Nordic Journal of Nursing Research \& Clinical Studies 2005; 25:10-4.

Axelsson E, Määttä S. Tactile touch as treatment for youths suffering from anorexia nervosa [Swedish]. Nordic Journal of Nursing Research \& Clinical Studies 2007;27:35-9.

Benner P. From Novice to Expert. New Jersey: Prentice Hall; 2000.

Billhult A, Bergbom I, Stener-Victorin E. Massage relieves nausea in women with breast cancer who are undergoing chemotherapy. Journal of Alternative \& Complementary Medicine 2007;13:53-7.

Corner J, Cawley N, Hildebrand S. An evaluation of the use of massage and essential oils on the wellbeing of cancer patients. International Journal of Palliative Nursing 1995;1:67-73.

Corrigan I, Samuelson KAM, Fridlund B, Thome B. The meaning of posttraumatic stress-reactions following critical illness or injury and intensive care treatment. Intensive and Critical Care Nursing 2007;23:206-15.

Crisp R. Nicomachean ethics, Aristotle. Cambridge: Cambridge University Press; 2000.

Cuthbertson BH, Hull A, Strachan M, Scott J. Post-traumatic stress disorder after critical illness requiring general intensive care. Intensive Care Medicine 2004;30:450-5.

Field T. Touch therapy. Miami, USA: Churchill Livingstone; 2000.

Gelling L. The role of hope for relatives of critically ill patients: a review of the literature. Nursing Standard 1999;14:33-8.

Gelling L, Fitzgerald M, Blight I. Hope in ICU: a qualitative study exploring nurses' experience of the concept of hope. Nursing in Critical Care 2002:271-7.

Gjengedal E. Understanding a world critical illness. A phenomenological study of the experiences of respiratory patients and their caregivers. Department of Public Health and Primary Health Care, Division for Nursing Science University of Bergen; 1994. 
Granberg A, Engberg IB, Lundberg D. Patients' experiences of being critically ill or severely injured and cared for in intensive care unit in relation to the ICU-syndrome. Part 1. Intensive \& Critical Care Nursing 1998;14:294-307.

Gravlee GS. Aristotle on hope. Journal of the History of Philosophy 2000;38:461.

Griffiths J, Cohen J, Lawson A. Post-traumatic stress disorder and intensive care. Care of the Critically III 2005;21:37-9.

Hayes J, Cox C. Immediate effects of a five-minute foot massage on patients in critical care. Intensive \& Critical Care Nursing 1999;15:77-82.

Henricson $M$, Berglund A-L, Määttä S, Ekman R, Segesten K. The outcome of tactile touch on oxytocin in intensive care patients: a randomised controlled trial. Journal of Clinical Nursing 2008a; 17:2624-33.

Henricson M, Berglund A-L, Määttä S, Segesten K. A transition from nurse to touch therapist-a study of preparation before giving tactile touch in an intensive care unit. Intensive and Critical Care Nursing 2006;22:239-45.

Henricson M, Ersson A, Määttä S, Segesten K, Berglund A-L. The outcome of tactile touch on stress parameters in intensive care: a randomized controlled trial. Complementary Therapies in Clinical Practice 2008b;14:244-54.

Jevne RF. It all begins with hope. San Diego: Lura Media; 1991.

Johansson Hovstadius E, Styvberg E-M, Wendt A. Touch massage aimed at instilling a sense of calm in intensive care patients. An evaluation by caregivers and patients [Swedish]. Nordic Journal of Nursing Research \& Clinical Studies 2005;25:52-5.

Jones C, Griffiths RD, Humphris G, Skirrow PM. Memory, delusions, and the development of acute posttraumatic stress disorderrelated symptoms after intensive care. Critical Care Medicine 2001;29:573-80.

Lincoln YS, Guba EG. Naturalistic inquiry. Newbury Park, CA: Sage; 1985.

Lindseth A, Norberg A. A phenomenological hermeneutical method for researching lived experience. Scandinavian Journal of Caring Sciences 2004;18:145-53.

Löf L, Berggren L, Ahlstrom G. Severely ill ICU patients recall of factual events and unreal experiences of hospital admission and ICU stay -3 and 12 months after discharge. Intensive and Critical Care Nursing 2006;22:154-66.

Magnus VS, Turkington L. Communication interaction in ICUpatient and staff experiences and perceptions. Intensive and Critical Care Nursing 2006;22:167-80.

Malterud K. Qualitative research: standards, challenges, and guidelines. Lancet 2001;358:483-8.

Marcel G. Homo Viator. Introduction to a metaphysic of hope. New York: Harper \& Row; 1965.
Marcel G., Desire and Hope. In Lawrence \& O’Connor (Eds.). Reading in existential phenomenology, Prentice-Hall Inc., New Jersey, 1967, p. 277-85.

Mishler E. Research Interviewing. Context and narrative. Cambridge, Massachusetts and London: Harvard University Press; 1991.

Olsson I, Rahm V, Högberg $\mathrm{H}$. Tactile massage after a stroke and improved quality of life [Swedish]. Nursing Science \& Research in the Nordic Countries 2004;24:21-6.

Ricoeur P. Interpretation and theory: discourse and the surplus of meaning. Texas: Christian University Press; 1976.

Ricoeur P. Hermeneutics and the Human Sciences, Editions de la Maison des Sciences de l'Homme and Cambridge University Press, Paris and Cambridge, 1998.

Ringdal M, Johansson L, Lundberg D, Bergbom I. Delusional memories from the intensive care unit-experienced by patients with physical trauma. Intensive and Critical Care Nursing 2006;22:346-54.

Rotondi AJ, Chelluri L, Sirio C, Mendelsohn A, Schulz R, Belle S, Im K, Donahoe M, Pinsky MR. Patients' recollections of stressful experiences while receiving prolonged mechanical ventilation in an intensive care unit. Critical Care Medicine 2002;30:74652.

Storli SL, Lindseth A, Asplund K. A journey in quest of meaning: a hermeneutic-phenomenological study on living with memories from intensive care. Nursing in Critical Care 2008;13:8696.

Taylor A. The principles and practice of physical therapy. 3rd ed. Cheltenham: Stanley Thomas; 1991.

Thomsson H. Reflexiva intervjuer [Swedish]. Lund: Studentlitteratur; 2002.

van Manen M. Researching lived experience. Human science for action sensitive pedagogy. New York: State University of New York Press; 1990.

Verhaeghe S, van Zuuren F, Defloor T, Duijnstee M, Grypdonck M. How does information influence hope in family members of traumatic coma patients in intensive care unit? Journal of Clinical Nursing 2007a;16:1488-97.

Verhaeghe S, van Zuuren F, Defloor T, Duijnstee M, Grypdonck M. The process and the meaning of hope for family members of traumatic coma patients in intensive care. Qualitative Health Research 2007b;17:730-43.

Wilkinson S, Aldridge J, Salmon I, Cain E, Wilson B. An evaluation of aromatherapy massage in palliative care. Palliative Medicine 1999;13:409-17.

Wåhlin I, Ek A-C, Idvall E. Patient empowerment in intensive care-an interview study. Intensive and Critical Care Nursing 2006;22:370-7. 